\title{
Disinfection tackling the COVID-19 pandemic causes disinfection by-products (DBPs) accumulation and threatens aquatic ecosystems
}

\section{Xian Zhang}

Tsinghua University

\section{Leyun Wang}

Tsinghua University

\section{Shanshan Chen}

Tsinghua University

Haibo Ling

Hubei Academy of Environmental Sciences

\section{Weiwei Li}

Hubei Academy of Environmental Sciences

Chuan Yi

Hubei Academy of Environmental Sciences

\section{Xinzi Wang}

Tsinghua University

\section{Yucheng Xie}

Tsinghua University

Liu Yi

Tsinghua University

Jiuhui Qu

Tsinghua University

\section{Xia Huang}

Dayi Zhang ( $\nabla$ zhangdayi@tsinghua.org.cn )

Tsinghua University https://orcid.org/0000-0002-4175-5982

\section{Article}

Keywords:

Posted Date: June 22nd, 2021

DOI: https://doi.org/10.21203/rs.3.rs-608546/v1 
License: (c) (i) This work is licensed under a Creative Commons Attribution 4.0 International License. Read Full License 


\section{Disinfection tackling the COVID-19 pandemic causes disinfection by- products (DBPs) accumulation and threatens aquatic ecosystems}

Xian Zhanga, Leyun Wang ${ }^{a}$, Shanshan Chen ${ }^{a}$, Haibo Ling ${ }^{b}$, Weiwei Li ${ }^{b}$, Chuan Yib ${ }^{b}$, Xinzi

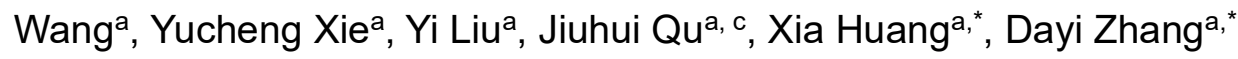

a State Key Joint Laboratory of Environment Simulation and Pollution Control, School of Environment, Tsinghua University, Beijing 100084, P.R. China

b Hubei Academy of Environmental Sciences, Wuhan 430072, P.R. China

c Key Laboratory of Drinking Water Science and Technology, Research Center for EcoEnvironmental Sciences, Chinese Academy of Sciences, Beijing 100085, P.R. China

\section{Corresponding author}

Prof. Xia Huang

School of Environment, Tsinghua University, Beijing 100084, P.R. China

Tel: +86(0) 10-62772324; Fax: +86(0)10-62795687

Email: xhuang@tsinghua.edu.cn

Dr Dayi Zhang

School of Environment, Tsinghua University, Beijing 100084, P.R. China

Tel: +86(0)10-62773232; Fax: +86(0)10-62795687

Email: zhangdayi@tsinghua.edu.cn 


\section{Abstract}

To fight against the coronavirus infectious disease-2019 (COVID-19), chlorine-based disinfectants are extensively or even over used for water, surface and personal care decontamination. The risks of disinfection by-products (DBPs) have been alerted to cause serious secondary pollution; however, there is still lack of evidence. This study collected 110 water samples from nine lakes and two rivers in Wuhan during the COVID-19 pandemic and comprehensively analyzed the occurrence of eighteen DBPs. Trihalomethanes, halonitromethanes, halogen acetonitriles and nitrosamines had a high detection frequency and were 0.99-14.26, ND-4.62, ND-1.09 and 0.0414-0.0861 $\mu \mathrm{g} / \mathrm{L}$, respectively, all lower than the maximum contamination level (MCL) suggested by China and USA. Haloacetic acids were detected in all lakes and Yangtze River and ranged from 33.8 to $856.1 \mu \mathrm{g} / \mathrm{L}$, much higher than the MCL. Haloacetic acids and halogen acetonitriles accounted for $74.2-95.1 \%$ of the total cytotoxicity $\left(0.38-3.62 \times 10^{5}\right)$; halonitromethanes $(94.0-98.7 \%)$ contributed to the majority of genotoxicity $\left(0.52-5.17 \times 10^{4}\right)$. Dichloroacetic acid exhibited significant ecological risks to green algae in two lakes and Yangtze River (risk quotient $>10$ ), and all the other DBPs showed negligible risks (risk quotient $<0.01$ ) to fish, daphnid or green algae. Correlation and redundancy analysis identified strong correlations between total organic carbon, conductivity, $\mathrm{NH}_{3}-\mathrm{N}$, turbidity and DBPs. DBP composition and the fluorescence indices of dissolved organic matters together categorized all lakes into two types. Type-I lakes contained all DBP categories, driven by total organic carbon and secondarily formed by residual active chlorine with natural organic matters; Type-II lakes and Yangtze River only had high levels of haloacetic acids and small amounts of trihalomethanes, explained by the primary formation of DBPs in sewage. Our findings for the first time uncovered the significant accumulation and risks of DBPs in lakes and rivers of Wuhan during the COVID-19, provided the evidence of secondary pollution from intensive disinfection activities with chlorine-based disinfectants, 
evaluated the potential the ecological risks of DBPs in Wuhan and along Yangtze River, and raised our re-consideration of disinfection strategy in the pandemics and postCOVID-19 era.

Keywords: COVID-19; disinfection strategy; disinfection by-products; ecological risks 


\section{1. Introduction}

2 Coronavirus disease 2019 (COVID-19) caused by severe acute respiratory syndrome

3 coronavirus 2 (SARS-CoV-2) has aroused over 160 million cases and 3.4 million deaths

4 until $10^{\text {th }}$ May, 2021. Fecal-oral transmission route is reported by World Health

5 Organization (WHO) for the spread of SARS-CoV-2 ${ }^{1}$, and some evidences show the

6 spillover of SARS-CoV-2 from wastewater ${ }^{2}$ or solid wastes ${ }^{3}$. Disinfection is therefore

7 used as the most effective strategy to prevent SARS-CoV-2 from spreading. Viable

8 disinfectants for SARS-CoV-2 outlined by the United States Environmental Protection

9 Agency (USEPA) include chlorine-based disinfectants, hydrogen peroxide, ethanol,

10 octanoic acid, peroxyacetic acid and quaternary ammonium ${ }^{4}$. Among them, chlorine-

11 based disinfectants are most used because of its potency and low price ${ }^{5,6}$. Particularly,

12 Chinese government has expended a huge amount of chlorine-based disinfectants for

13 both indoor and outdoor spaces, and at least 2000 tons of disinfectants are estimated to

14 use in Wuhan alone in the initial stage of the COVID-19 pandemic ${ }^{7}$. These disinfectants

15 may eventually adduct and accumulate in lakes and rivers through runoff and sewage,

16 posing a significant threat to aquatic ecosystem and drinking water safety ${ }^{8}$. However,

17 there is still lack of evidence on the hypothetical consequence from disinfectant overuse

18 during the COVID-19 pandemic.

19 Chlorine-based disinfectants can directly destroy cell walls or oxidize proteins of 20 organisms $^{8}$. In addition, they can react with various kinds of organic matters, e.g., natural 21 organic matters, effluent suspended solids, microorganisms, algal toxins, and 22 anthropogenic contaminants, to form unintended disinfection by-products (DBPs) ${ }^{9,10}$. Up

23 to now, more than 800 DBPs have been identified, including trihalomethanes (THMs), 24 haloacetic acids (HAAs), halogen acetonitriles (HANs), halonitromethanes (HNMs), 25 haloacetamides (HAcAms), haloketones (HKs) and nitrosamines (NAs). Since many 26 DBPs are reported to possess cytotoxicity, mutagenicity, genotoxicity, and/or 
teratogenicity, increasing concerns are raised for public health ${ }^{11}$. Microorganisms, plants and animals in aquatic ecosystems are highly vulnerable to environmental insult from residual DBPs, which in turn affects human beings by biomagnification through the food chain ${ }^{12}$. Yadav et al. reported the effects of DBPs on microorganisms that both microbial diversity and community structure of aquatic ecosystem were altered after disinfection ${ }^{13}$. THM exposure leads to developmental anomalies of zebrafish, and HAAs including tribromoacetic acid (TBA) and dichloroacetic acid (DCAA) are responsible for embryo malformations ${ }^{14}$. DBPs exposure occurs in three ways including inhalation, ingestion and dermal absorption, leading to high levels of skin permeable and volatile DBPs in the blood 15,16. Several epidemiological studies have suggested that long-term exposure to DBPs is related to adverse human health outcomes including higher incidence of bladder and colorectal cancer ${ }^{17,18}$. Since THMs are soluble in fat and also highly volatile, they are found in various food such as ice cream, juices and soft drinks. In addition, THMs are reported to bioaccumulate in adipose tissue, kidneys, lungs and liver when quantity and route being exposed 19,20 . Previous studies have suggested that many DBPs are intermediate compounds that can transform into other end products by hydrolysis or chlorination ${ }^{21}$. For example, HANs are susceptible to further convert to haloacetic acids, especially trihaloacetonitriles ${ }^{22}$. Accordingly, many DBPs have been classified as potential carcinogenic compounds to humans by International Agency for Research on Cancer (IARC) ${ }^{15}$.

Several regulatory guidelines are established by authorities like WHO, USEPA and Bureau of China Standard for DBPs in drinking water. The maximum contamination level (MCL) is $80 \mu \mathrm{g} / \mathrm{L}$ for THMs and $60 \mu \mathrm{g} / \mathrm{L}$ for HAAs in USA ${ }^{23}$. In China, it is $60 \mu \mathrm{g} / \mathrm{L}$ for trichloromethane (TCM), $60 \mu \mathrm{g} / \mathrm{L}$ for monobromodichloromethane (BDCM), $100 \mu \mathrm{g} / \mathrm{L}$ for dibromochloromethane (DBCM), $100 \mu \mathrm{g} / \mathrm{L}$ for tribromethane (TBM), $50 \mu \mathrm{g} / \mathrm{L}$ for dichloroacetic acid (DCAA) and $100 \mu \mathrm{g} / \mathrm{L}$ for trichloroacetic acid (TCAA) ${ }^{24}$. These 
guidelines mainly focus on drinking water or swimming pool; however, limited studies address DBPs in natural waters, particularly after the intensive disinfection activities in the pandemics like COVID-19, when excessive DBPs in chlorinated sewage effluents and surrounding soils eventually extravasate into the receiving surface waters and contaminate the drinking water sources. As COVID-19 continues to spread across the world, the increasing consumption of chlorine-based disinfectants and production of DBPs might result in a global secondary disaster in aquatic ecosystems ${ }^{7}$. Therefore, it is of great significance to assess the occurrence, distribution and impacts of DBPs in aquatic ecosystems.

Till now, only two studies reported the occurrence and distribution of DBPs in several rivers and lakes during the COVID-19 pandemic in China ${ }^{25,26}$ and did not find a significant increase. There is still lack of a comprehensive survey targeting a broad range of water sources in megacities. This work studied the levels and compositions of DBPs in 110 water samples from nine lakes and two rivers in Wuhan in the initial stage of the COVID2019, and for the first time found a significant accumulation and unneglected risks of HAAs in natural waters. We aimed to evaluate the levels of DBPs in lakes and rivers, assess their toxicities and ecological impacts, and explain the formation mechanisms of DBPs by exploring the organic matter compositions in these aquatic systems. Our findings highlight the secondary environmental risks after the intensive disinfection activities in the pandemics, and offer suggestions for disinfection strategies and DBPs risk management in natural waters.

\section{Results}

\subsection{Levels of key DBPs in lakes and rivers}

Mean concentrations and compositions of key DBPs in 110 water samples are illustrated in Figure 2. Among them, HAAs (33.8-856.1 $\mu \mathrm{g} / \mathrm{L})$ were of the highest level in lakes, 
followed by THMs (0.99-14.3 $\mu \mathrm{g} / \mathrm{L})$, HNMs (ND-4.62 $\mu \mathrm{g} / \mathrm{L})$, HANs (ND-1.09 $\mu \mathrm{g} / \mathrm{L})$ and NAs $(0.0414-0.0861 \mu \mathrm{g} / \mathrm{L})$. Only DCAA was detected among three HAAs and the concentration exceeded the MCL of the Standards for Drinking Water Quality of China (GB5749-2006) except for samples from MSH. The highest mean concentration of HAAs was observed in JYH $(856.1 \mu \mathrm{g} / \mathrm{L})$, followed by $\mathrm{NH}(330.1 \mu \mathrm{g} / \mathrm{L})$ and $\mathrm{HH}(123.7 \mu \mathrm{g} / \mathrm{L})$. Other DBPs were all below the MCL. For river samples, only waters from Yangtze River (YR) had a wide variety of DBPs, and HAAs had the highest concentration (mean 487.1 $\mu \mathrm{g} / \mathrm{L}$ ), approximately 8.7 times higher than the MCL. In contrast, only limited DBPs were detected in $\mathrm{HR}$, and none of them exceeded the MCL.

\subsection{DBPs composition}

The composition of individual THMs, HANs, HNMs and NAs in water samples are illustrated in Figure 3. It is clear that waters from five lakes of $\mathrm{HJH}, \mathrm{NH}, \mathrm{LZH}, \mathrm{MSH}$ and HGH had high levels of TCM (1.14-6.91 $\mu \mathrm{g} / \mathrm{L}$, Figure 3A), DBCM (1.36-7.35 $\mu \mathrm{g} / \mathrm{L}$, Figure 3A), TCAN (0-0.45 $\mu \mathrm{g} / \mathrm{L}$, Figure 3B) and TCNM (0.48-4.62 $\mu \mathrm{g} / \mathrm{L}$, Figure $3 \mathrm{C})$, designated as the type-I lakes. For the other four lakes of $\mathrm{DH}, \mathrm{HH}, \mathrm{JYH}$ and TXH (the type-II lakes), they only had a low level of TCM $(0.13-0.16 \mu \mathrm{g} / \mathrm{L})$ and DBCM $(0.84-1.33 \mu \mathrm{g} / \mathrm{L})$, whereas TCAN and TCNM were non-detectable. Waters from both YR and HR were similar as those from the type-II lakes, containing mainly DBCM (2.24 and $1.52 \mu \mathrm{g} / \mathrm{L}$, respectively). It is worth mentioning that the concentrations and compositions of NAs, which were not DBPs from chlorine-based disinfectants, were similar across all water samples (Figure 3D). More precisely, NDMA (0.00836-0.0566 $\mu \mathrm{g} / \mathrm{L})$ and NDEA $(0.00408-0.0379 \mu \mathrm{g} / \mathrm{L})$ were the predominant NAs, followed by NPYR $(0.00192-0.00998 \mu \mathrm{g} / \mathrm{L})$ and NPIP (N.D.$0.0181 \mu \mathrm{g} / \mathrm{L})$

\subsection{Toxicity and ecological risks of DBPs in lakes and rivers}

The cytotoxicity indices and fractions of each DBPs in lakes and rivers of Wuhan are illustrated in Figure 4A and 4B, respectively. Total DBPs cytotoxicity ranged from $3.80 \times 10^{4}$ 
$105(\mathrm{HGH})$ to $3.62 \times 10^{5}(\mathrm{JYH})$ in lakes. HAAs and HANs accounted for $74.2-95.1 \%$ of total

106 DBPs cytotoxicity, which was approximately 1-3 orders of magnitude higher than THMs,

107 HNMs or NAs. Both HAAs and HANs exhibited the major cytotoxicity in the type-I lakes, 108 whereas HAAs dominated the cytotoxicity in the type-Il lakes. Only DBPs in the type-I

109 lakes exhibited significant genotoxicities ranging from $5.24 \times 10^{3}$ to $5.17 \times 10^{4}$ (Figure $4 \mathrm{C}$ ).

110 HNMs contributed to the majority of genotoxicities (94.0-98.7\%), approximately 16.0-49.4

111 times higher than HANs.

$112 \mathrm{RQs}$ represent the potential ecological risks of DBPs in aquatic ecosystem, and our data

113 suggested neglectable risks of DBPs to fish and daphnid in lakes and rivers of Wuhan,

114 as their RQs were less than 0.1 (Figure $5 A$ and $5 B$ ). Nevertheless, DCAA exhibited

115 significant ecological risks to green algae, which were adverse in HJH, JYH and YR

$116(R Q s>10)$ and moderate in other seven lakes $(1.0<R Q s<10)$ (Figure $5 C)$. All the other

117 DBPs showed insignificant risks $(R Q s<0.01)$ to green algae.

$118 \quad 2.4$ Water physiochemical variables and DOMs

119 The physiochemical variables of 110 surface waters in Wuhan are listed in Table 1 . The 120 mean values of $\mathrm{pH}$, conductivity, turbidity, $\mathrm{NH}_{3}-\mathrm{N}, \mathrm{TN}$ and TP were 6.64-8.63, 114.0-

$121358.64 \mu \mathrm{S} / \mathrm{cm}, 1.85-38.81 \mathrm{NTU}, 0.08-0.52 \mathrm{mg} / \mathrm{L}, 0.52-2.94 \mathrm{mg} / \mathrm{L}$ and $0.02-0.21 \mathrm{mg} / \mathrm{L}$,

122 respectively. TOC ranged from $2.72 \pm 0.18$ to $16.0 \pm 9.03 \mathrm{mg} / \mathrm{L}$ and $\mathrm{HJH}$ were the highest.

123 COD ranged from $2.97 \pm 1.80 \mathrm{mg} / \mathrm{L}$ to $61.5 \pm 21.7 \mathrm{mg} / \mathrm{L}$ and was highest in $\mathrm{HH}$.

124 Typical EEM spectra of natural DOMs in lakes and rivers are shown in Figure 6A. The 125 spectra exhibited some similarities in peak locations among DOMs from the nine lakes, 126 such as region IV (microbial by-products) and region $\mathrm{V}$ (humic acids). The peaks of

127 tryptophan-like proteins in region II were prominent, whereas the peaks of tyrosine-like 128 proteins in region I were less noticeable. Figure 6B illustrated a similar distribution of FRI 129 among all lakes and rivers. Region II (22.7-29.2\%) was the highest for all samples, 130 followed by region III (19.3-27.1\%), region IV (12.9-23.1\%), region $\mathrm{V}(11.7-22.3 \%)$ and 
131 region I (10.7-20.4\%). These indicated the presence of many tryptophan-like proteins and

132 fulvic acids in water resources of Wuhan. More precisely, HIX values (1.83-3.31) were

133 less than 4.0 (Figure 6B), suggesting a weak humification degree of DOMs. BIX values

134 ranging from 0.90 to 1.65 suggested the autochthonous production of most natural DOMs.

135 In most lakes, FI values ranged from 1.92 to 2.15 and NOMs were freshly produced from

136 biological activities, whereas the lower FI values in LZH (1.73), YR (1.83) and HR (1.72)

137 documented their formation from both microbial and terrestrial activities. Peak T/C values

138 in YR (1.21) and HR (1.41) were much lower than those in lakes (1.54-3.39), indicating

139 poorer biodegradability of natural DOMs in rivers.

$140 \quad 2.5$ Links between DBPs, water physiochemical variables and DOMs

141 Correlation analysis (Figure 7A) showed the relationships between DBPs, water 142 physiochemical variables and FI indices of natural DOMs. Among DBPs, there were 143 significant and positive correlations between HANs and HNMs $\left(r^{2}=0.66, p<0.05\right)$, THMs 144 and HNMs $\left(r^{2}=0.51, p<0.05\right)$, THMs and HANs $\left(r^{2}=0.41, p<0.05\right)$. These hinted similar 145 precursors for the formation of THMs, HNMs and HANs. Among water physiochemical 146 variables, TOC exhibited significant and positive correlations with HNMs $\left(r^{2}=0.45, p<0.05\right)$, 147 THMs $\left(r^{2}=0.23, p<0.05\right)$ and HANs $\left(r^{2}=0.21, p<0.05\right)$, further confirming similar organic 148 precursors for the formation of HNMs, THMs and HANs. The positive correlation between $149 \mathrm{NH}_{3}-\mathrm{N}$ and HANs $\left(r^{2}=0.21, p<0.05\right)$ suggested the important roles of ammonia in HANs 150 formation. Conductivity was positively correlated with HAAs $\left(r^{2}=0.22, p<0.05\right)$, but 151 exhibiting negative correlations with HNMs $\left(r^{2}=-0.30, p<0.05\right)$, THMs $\left(r^{2}=-0.51, p<0.05\right)$ 152 and HANs $\left(r^{2}=-0.23, p<0.05\right)$. Among $F R I$, region I exhibited significant and positive 153 correlations with THMs $\left(r^{2}=0.23, p<0.05\right)$ and HAAs $\left(r^{2}=0.34, p<0.05\right)$, indicating that 154 tyrosine-like proteins may be crucial precursors of both THMs and HAAs. Region III $155\left(r^{2}=0.25, p<0.05\right)$ and Region IV $\left(r^{2}=-0.29, p<0.05\right)$ was positively and negatively 156 correlated with THMs, respectively. Region $\mathrm{V}$ exhibited significant and negative 
157 correlations with HAAs $\left(r^{2}=-0.31, p<0.05\right)$. Among fluorescence indices, there were

158 negative correlations between $\mathrm{HIX}$ and HAAs $\left(r^{2}=-0.23, p<0.05\right)$, and $\mathrm{BIX}$ and $\mathrm{HNMs}\left(r^{2}=-\right.$

$159 \quad 0.22, p<0.05)$.

160 RDA score plot between water physiochemical variables and DPBs (Figure 7B) illustrates

161 that the first (RDA1) and second (RDA2) components explained $19.76 \%$ and $2.58 \%$ of

162 the total variance, respectively. Among all the variables, conductivity $(10.4 \%, p=0.002)$,

$163 \operatorname{TOC}(7.1 \%, p=0.004)$, turbidity $(3.3 \%, p=0.02)$ and $\mathrm{NH}_{3}-\mathrm{N}(3.0 \%, p=0.042)$ contributed to

164 the major variance of DBP composition. Water samples from the type-I lakes, type- I I

165 lakes and rivers were clearly separated. DBPs in the type-I lakes were mainly linked with

166 TOC, whereas conductivity had more critical roles in the type-Il lakes and two rivers,

167 segregated by $\mathrm{NH}_{3}-\mathrm{N}$. As for fluorescence indices of DOMs, they together explained

$16820.88 \%$ of the total variance of DBP composition (Figure $7 C$ ). Peak T/C $(4.1 \%, p=0.02)$

169 and Region IV $(3.9 \%, p=0.01)$ were significant variable.

170

171 3. Discussion

172 To fight against COVID-19, chlorine-based disinfectants are extensively or even over

173 used for water, surface and personal care decontamination, raising the concerns about

174 the formation, release and accumulation of DBPs in surrounding environment ${ }^{7}$.

175 Disinfection with chlorine-based disinfectants can directly generate high levels of DBPs

176 in sewage and sludge, and the residual active chlorine might further react with NOMs in

177 natural waters or sediments, causing secondary contamination in lakes, rivers and even

178 surrounding soils ${ }^{8}$. These DBPs hypothetically extravasate into the receiving rivers and

179 lakes, posing a great risk to aquatic ecosystem and public health ${ }^{7}$. Till now, there is still

180 lack of direct evidence, and our study is the first report unraveling the secondary pollution

181 and ecological risks of DBPs in lakes and drinking water sources of Wuhan, resulted from

182 disinfectant overuse during the COVID-19 pandemic. Our findings comprehensively 
visualized the occurrence and distribution of eighteen DBPs, assessed their toxicities and

184 ecological risks, and discussed the formation mechanisms, showing great significance to

185 evaluate the consequence of intensified disinfection on aquatic ecosystem.

186 DBP levels are reported to vary greatly across water samples, attributing to the difference

187 in disinfectant type, dosage, water physiochemical variables, and the presence of organic

188 and halogenated molecules in water ${ }^{27}$. Comparing to other previously reported DPBs

189 levels in wastewater effluents (13.5 to $234.2 \mu \mathrm{g} / \mathrm{L})^{28}$, drinking water (86.0-122.2 $\left.\mu \mathrm{g} / \mathrm{L}\right)^{29}$

190 and swimming pools $(85.2-224.0 \mu \mathrm{g} / \mathrm{L}){ }^{30}$ (Table 2), our results suggested a significant

191 increase and accumulation of DBPs in surface waters of Wuhan after using superfluous

192 disinfectants to decontaminate wastewater, surface and personal care in the COVID-19

193 pandemic. Particularly, HAAs were 33.8-856.1 $\mu \mathrm{g} / \mathrm{L}$ in almost all lakes and Yangtze River,

194 much higher than the MCL of the Standards for Drinking Water Quality of China (GB5749-

195 2006). Previous studies found different levels of HAAs in drinking water and wastewater

196 effluents, highlighting the necessity to prevent HAAs formation in drinking water

197 disinfection ${ }^{23,28}$. Nevertheless, HAAs accumulation in natural surface water has not been

198 reported, and the significant increasing HAAs in lakes and rivers of Wuhan in this study

199 prove that intensive disinfection in megacities during the COVID-19 pandemic can cause

200 remarkable DBP contamination in surface water and raises special concerns of 201 disinfection strategy.

202 DBP composition in surface waters of Wuhan was different from other studies. THMs 203 were normally the most prevalent chlorinated DBPs ${ }^{23}$, whereas they were much lower in 204 our study, only ranging from 0.99 to $14.26 \mu \mathrm{g} / \mathrm{L}$ and accounting for $0.52-21.11 \%$ of total 205 DBPs. In contrast, the average levels of HAAs (33.8-856.1 $\mu \mathrm{g} / \mathrm{L})$ were much higher and 206 dominated DBPs, consistent with Lee's work that HAAs (35.2-747.1 $\mu \mathrm{g} / \mathrm{L})$ was main DBPs 207 in chlorinated-swimming pool water, accounting for $72.6 \%$ of total DBPs ${ }^{31}$. It might be 208 explained by higher volatility and stability of THMs than HAAs in natural environment. 
209 Unlike previous laboratory studies collecting samples promptly after the addition of

210 chlorine-based disinfectants, it normally takes several hours to days for lakes and rivers

211 to receive sewage containing DBPs from pipeline networks, which have many lifting and

212 pumping operations from disinfection points to the final receiving water ${ }^{16}$. Highly volatile

213 chemicals like THMs are therefore easier to evaporate into atmosphere and their

214 concentrations then decline in natural water. Another possible explanation is the

215 secondary formation of DBPs in the receiving water due to the excess active chlorine

216 residual in sewage after intensive disinfection activities. Higher temperature, microbial

217 activities and DOMs are reported to benefit HAA formation ${ }^{23,32}$. In this study, the lakes

218 and rivers of Wuhan had poor water quality with high levels of COD and TOC. More

219 precisely, COD in $\mathrm{HH}$ exceeded the standard of Class $\mathrm{V}$ according to the Environmental

220 Quality Standards for Surface Water (GB 3838-2002) regulated by Chinese Ministry of

221 Health ${ }^{33}$. Together with the relatively higher temperature ranging from 15 to $30{ }^{\circ} \mathrm{C}$ during

222 the sampling period, more HAAs might be formed than THMs in natural surface waters.

223 Last but not the least, higher dosage and residuals of chlorine-based disinfectants can

224 favor the formation of HAAs over THMs ${ }^{34}$. Accordingly, HAAs rather than other DBPs

225 exhibited a striking high level in lakes and rivers of Wuhan, and they should be specifically

226 monitored in other surface waters receiving disinfected sewage in cities with intensive

227 disinfection activities to fight against COVID-19.

228 Besides total amount, each DBP category exhibited unique compositions comparing to 229 previous studies. TCM and DBCM were the dominant THMs in lakes and rivers of Wuhan, 230 and BDCM and TBM were not detected (Figure 3A). It was different from another study 231 reporting high levels of TCM $(20.9 \mu \mathrm{g} / \mathrm{L}$, approximately $90 \%$ of THMs $)$ but neglectable $232 \mathrm{DBCM}$ and TBM $(<0.2 \mu \mathrm{g} / \mathrm{L})$ in chlorinated swimming pool waters ${ }^{31}$. Among HAAs, only 233 DCAA was detected in lakes and YR, while TCAA and MCAA were non-detectable. Other

234 studies have inconsistent results that TCAA was the most common HAAs, followed by 
235 DCAA, DBCAA, MCAA and MBAA, in drinking water ${ }^{23}$, chlorinated wastewater effluents

$236{ }^{28}$, and chlorinated swimming pools ${ }^{31}$. The low levels of HANs in our study (ND-1.09 $\left.\mu \mathrm{g} / \mathrm{L}\right)$

237 were consistent with other studies on drinking water $(0.6-24 \mu \mathrm{g} / \mathrm{L}){ }^{28}$ and wastewater

238 effluents (2.9-48.6 $\mu \mathrm{g} / \mathrm{L}){ }^{31}$. However, TCAN was the major HANs (Figure 3B), different

239 from a study on the chlorinated swimming pool waters that DCAN (74.7\%), BCAN (15.8\%)

240 and DBCN (9.5\%) were predominant HANs and TCAN was below the limit of detection

241 31. Only TCNM was detected among all HNMs in lakes (Figure 3C) and similar with the

242 concentrations in the chlorinated drinking water $(0.16-1.5 \mu \mathrm{g} / \mathrm{L})^{28}$, meeting well with

243 previous studies that the TCNM (>94\%) were the major HNMs in chlorinated water ${ }^{35,36 .}$

244 The dominance of TCAN and TCNM might be explained by slow decomposition of TCAN

245 through hydrolysis and natural transformation from HCNM to TCM ${ }^{31}$. Our results

246 suggested that DBPs in natural surface waters receiving sewage containing DBPs from

247 intensive disinfection during the COVID-19 pandemic had unique signature and

248 compositions.

249 We only found $\mathrm{ng} / \mathrm{L}$ level of NAs in lakes and rivers of Wuhan (Figure 3D), consistent with

250 previous studies on drinking waters and wastewater effluents ${ }^{28,37}$. Particularly, NDMA

251 and NDEA were predominant NAs (Figure 3D), similar as a study on river waters that

$252 \operatorname{NDMA}(0.0015-0.017 \mu \mathrm{g} / \mathrm{L})$ and NDEA $(0.0014-0.0095 \mu \mathrm{g} / \mathrm{L})$ were major NAs ${ }^{38}$. Wang et

253 al. reported that wastewater effluents from upstream cities might be a crucial source of

254 NAs ${ }^{35}$, and the tap water in megacities like Shanghai are heavily polluted by NAs 255 compared to other areas along Yangtze River. As NAs are formed by the reactions 256 between monochloramine and organic amine precursors ${ }^{37}$ or nitrite chlorination in the 257 presence of nitrosamine precursor ${ }^{17}$, they are not correlated with the intensively used 258 chlorine-based disinfectants during the COVID-19 pandemic in Wuhan. Accordingly, all

259 NAs had similar concentrations and compositions across all lakes and rivers in this study, 260 documenting a DBP background from other disinfection activities. 
261 According to the occurrence and composition of DBPs, two types of lakes were classified

262 in Wuhan (Figure 3). Type-I lakes (HJH, NH, LZH, MSH and $\mathrm{HGH}$ ) had high levels of 263 TCM, DBCM, TCAN and TCNM (Figure 3), and they are mainly located in urban areas 264 with higher population and disinfection density. The intensive disinfection activities in 265 these regions left excessive disinfectants on roads and surrounding soils, eventually 266 extravasating into the receiving lakes through rain pipes after rain off ${ }^{25}$. These residual 267 disinfectants might react with NOMs in lakes and formed secondary DBPs. It was 268 supported by the higher explanation of TOC in DBPs composition in RDA score plots 269 (Figure 7B) and positive correlations between three kinds of DBPs (HANs, HNMs, THMs) and TOC in PCA score plots (Figure 7A). Further evidence comes from the structural 271 characteristics of DOMs across lakes and rivers using EEM spectra, which provide 272 information of chromophores and fluorophores ${ }^{39}$. DOMs in type-l lakes exhibited low 273 HIXs (<4.0), high BIXs (0.90 to 1.12), moderate Fls (1.72-2.06), and high Peak T/C (1.53274 2.71), suggesting weak humification, autochthonous and microbial-driven features ${ }^{40}$. 275 Previous studies revealed that THMs were strongly correlated with humic-like 276 components (region V) ${ }^{41}$. Despite the similar distribution of region V between type-I (11.8$27720.9 \%)$ and type-II (11.7-22.3\%) lakes, TOC in type-I lakes (5.10-16.0 mg/L) were much 278 higher than type-II lakes (4.95-8.00 mg/L), indicating higher levels of precursors for THMs.

279 Similarly, the precursors for HANs strongly correlated with protein-like component (region 280 I and II) ${ }^{42}$, which were also remarkably higher in type-I lakes than in type- II lakes.

281 In contrast, type-II lakes (DH, HH, JYH and TXH) only had a low level of TCM and DBCM 282 (Figure 3), and they are in suburban regions with lower population density, large area and 283 mainly rain-sewage mixed flow pipelines. There were relatively weaker disinfection 284 activities, and the low levels of residual disinfectants in runoff might directly react with 285 DOMs in sewage in the pipelines and only primary DBPs were formed. Therefore, type-II 286 lakes exhibited different DBPs composition, predominantly explained by conductivity, 
turbidity and $\mathrm{NH}_{3}-\mathrm{N}$ (main contaminants in sewage) in RDA results (Figure 7B). Similarly,

288 there are many discharge points of rain-sewage mixed or diversion pipelines along

289 Yangtze River (YR ${ }^{43}$, which received effluents from both type-I and type-II lakes and had

290 high levels of HAAs and small amounts of THMs (Figure 2A). Instead, Han River (HR) is

291 the main drinking water sources for Wuhan and nearly all the outfalls have been banned

292 since $2002{ }^{44}$. Therefore, Han River did not receive sewage containing high levels of

293 DBPs from intensive disinfection activities during the pandemic and there were only NAs

294 irrelevant to the chlorine-based disinfectants in HR (Figure 2A). Our findings proved that

295 the high levels of DBPs in Yangtze River were mainly derived from discharge from

296 pipelines and surrounding lakes, and the residual DBPs might spread and threaten the

297 downstream aquatic ecosystems of Yangtze River.

298 DBPs in lakes and rivers of Wuhan exhibited considerable cytotoxicities, significant

299 genotoxicities and non-neglectable ecological risks (Figure 4). Cytotoxicities were mainly

300 derived from HAAs and HANs, which were approximately 1-3 orders of magnitude higher

301 than THMs, HNMs or NAs (Figure 4A). More precisely, HAAs exhibited the highest

302 concentration (Figure 2A) and strong cytotoxicity 45 , contributing to the majority of

303 cytotoxicities (15.7-98.6\%) in lakes. As for HR containing neglectable HAAs and HANs,

304 NAs had the highest cytotoxicity (Figure 4B). Although THMs, HAAs and NAs were main

305 DBPs, neither of them exhibited genotoxicity or lack information (Table S2) ${ }^{46,47}$. Instead,

306 HNMs contributed to the major genotoxicities (94.0-98.7\%), approximately 16.0-49.4

307 times higher than HANs. All DBPs exhibited limited or nonnegligible ecological risks to

308 fish, daphnid and green algae in lakes and rivers of Wuhan (Figure 5A and 5B), except

309 for DCAA which imposed significant risks to green algae. All these results were consistent

310 with some previous reports about the cytotoxicities of HANs in wastewater effluents ${ }^{28,45}$,

311 major cytotoxicities of HANs and NAs in chlorinated effluents ${ }^{28}$, significant cytotoxicities

312 of HANs, haloacetaldehydes and HAAs in chlorinated saline groundwater ${ }^{48}$, stronger 
313 genotoxicities of nitrogen-containing HANs and HNMs ${ }^{49}$ in disinfected recreational pools

$314^{50}$, and remarkable ecological risks of HAAs for green algae in chlorinated wastewater

315 effluents ${ }^{28}$. Comparing to other studies on wastewater effluents (cytotoxicities of $10^{5}-10^{7}$ )

$316{ }^{28}$ and drinking water (cytotoxicities of $10^{2}-10^{5}$ and genotoxicities of $10^{2}-10^{3}$ ) ${ }^{51}$, the risks

317 of DBPs in lakes and rivers of Wuhan were nonnegligible. Regarding the facts that some

318 lakes and HR are water sources of Wuhan and residual DBPs can transport to

319 downstream of Yangtze River, DBPs derived from intensive disinfection activities in

320 Wuhan had significant ecological risks and could threaten drinking water safety. It is

321 therefore of urgency to reconsider the disinfection strategies for the prevention and

322 control of emerging infectious diseases during the pandemics, and appropriate

323 disinfection management including disinfectant type and dosage is critical to mitigate

324 secondary environmental pollution in the post-COVID-19 era.

325

326 4. Conclusion

327 Our study first reported the increasing levels of DBPs, particularly HAAs, in lakes and 328 rivers of Wuhan during the initial stage of the COVID-19 pandemic. They were mainly

329 derived from the intensive disinfection activities in urban areas, and imposed 330 nonnegligible toxicities and significant ecological risks to surrounding receptors or even 331 downstream of Yangtze River. Additionally, the composition of DBPs varied across

332 surface waters and were remarkably different from previous studies on chlorinated 333 drinking water or wastewater, explained by the long-distance transport in sewage 334 pipelines and secondary formation with NOMs in surface waters. Our findings provide the

335 first evidence that the excessive disinfection activities in megacities during the pandemics 336 do dispense DBPs in the surrounding receiving waters and threaten aquatic ecosystems, 337 highlighting the importance for appropriate disinfection strategy and management for the 338 prevention and control of emerging infectious diseases during the pandemics. 


\section{Materials and Methods}

341

342 Eighteen DBPs, including four THMs (TCM, BDCM, DBCM and TBM), three HAAs

343 (monochloroacetic acid, MCAA; DCAA; TCAA), one HAN (trichloroacetonitrile, TCAN), one HNM (trichloronitromethane, TCNM) and nine NAs (N-nitrosomethylethylamine,

NMEA; N-nitrosopyridine, NPYR; N-nitromorpholine, NMOR; N-nitrosodiethylamine, NDMA; N-nitrosodiethylamine, NDEA; N-nitrosopiperidine, NPIP; N-nitrosodipropylamine, NDPA; N-nitrosodibutylamine, NDBA; N-nitrosodiphenylamine, NDphA) were investigated in this study. DBPs chemical standards were purchased from Sigma-Aldrich (USA) and stored at $4{ }^{\circ} \mathrm{C}$.

\subsection{Study area and sampling}

The study area is in Wuhan, Hubei Province (China), which is about $8569 \mathrm{~km}^{2}$ with estimated population of 11.2 million. As illustrated in Figure 1 and Table S1, two types of surface water including nine lakes (Huangjiahu Lake, HJH; Nanhu Lake, NH; Liangzihu Lake, LZH; Moshuihu Lake, MSH; Tangxun Lake, TXH; Houhu Lake, HH; Donghu Lake, DH; Houguanhu Lake, HGH; Jinyinhu Lake, JYH) and two rivers (Yangtze River, YR; Hanjiang River, HR) were collected in May and June 2020, which was the initial stage of the COVID-2019 pandemic. The distances between sampling sites were about 0.3-4.0 $\mathrm{km}$ and 2.0-9.0 km in lakes and rivers, respectively. All sampling sites in two rivers are drinking water sources of Wuhan. Water samples were transported to the laboratory within $4 \mathrm{~h}$, stored at $4{ }^{\circ} \mathrm{C}$ and filtered through a $0.2 \mu \mathrm{m}$ membrane filter prior to instrumental analysis.

\subsection{Chemical analysis of water physiochemical variables}

Total organic carbon (TOC) was analyzed on a Shimadzu TOC-Analyzer (TOC-L CPN, 
364 Japan). Chemical oxygen demand (COD), total phosphorus (TP), total nitrogen (TN) and

365 ammonia nitrogen $\left(\mathrm{NH}_{3}-\mathrm{N}\right)$ were analyzed according to the standard methods ${ }^{26}$. The $\mathrm{pH}$

366 and conductivity were measured with a WTW Multi 3410 equipped with a SenTix $940 \mathrm{pH}$

367 electrode (WTW, Germany) and an HI 9835 conductivity meter (Hanna, Italy), respectively.

\section{$368 \quad 5.4$ Excitation-emission matrix fluorescence spectroscopic analysis}

369 Besides anthropogenic sources, dissolved organic matters (DOMs) in natural waters are

370 well-recognized as the crucial precursors of DBP. As a complex mixture of organic matters

371 with diverse chemical structures and reactivities, DOMs were characterized by excitation-

372 emission matrix (EEM) fluorescence spectroscopy with high sensitivity and selectivity ${ }^{52}$,

373 using a Hitachi spectrofluorometer (F-7000 FL, Japan) at room temperature $\left(20-23{ }^{\circ} \mathrm{C}\right)$

374 with a 1-cm quartz cuvette. The test conditions were as follows: excitation wavelength

375 range: $200-400 \mathrm{~nm}$ (step $5 \mathrm{~nm}$ ), emission wavelength range: $250-500 \mathrm{~nm}$ (step $5 \mathrm{~nm}$ ),

376 scan speed: $2400 \mathrm{~nm} / \mathrm{min}$. The spectrofluorometer was auto-zeroed prior to analysis and

377 the fluorescence intensities were normalized by the Raman peak of Milli-Q water at $378 \lambda_{\mathrm{ex}}=348 \mathrm{~nm}$.

379 Fluorescence regional integration (FRI) and several fluorescence indices were used to

380 delineate EEM data. EEM peaks were first divided into five regions including aromatic

381 proteins such as tyrosine and tryptophan (regions I and II), fulvic acids (region III), soluble

382 microbial by-products (region IV) and humic acids (region V). The distribution of five

383 regions can be calculated according to a previous study ${ }^{53}$. The fluorescence indices of

384 humification index (HIX), autochthonous biological index (BIX), fluorescence index (FI)

385 and peak T/C (the intensity ratio of peak T to peak $\mathrm{C}$ ) were then calculated. HIX and BIX

386 reflects the humification degree and microbial aspect of DOM properties, respectively. FI

387 indicates the possibility of microbial production, and peak T/C indicates the

388 biodegradability of DOMs ${ }^{40}$. They were calculated by the following Equations (1) to (3). 


$$
\begin{gathered}
\mathrm{HIX}=\frac{\sum \mathrm{I}_{\mathrm{Em}} 435-480}{\sum \mathrm{I}_{\mathrm{Em}} 300-345}, \text { at } \mathrm{E}_{\mathrm{x}}=254 \mathrm{~nm} \\
\mathrm{BIX}=\frac{\mathrm{I}_{\mathrm{Em}} 380}{\mathrm{I}_{\mathrm{Em}} 430}, \text { at } \mathrm{E}_{\mathrm{x}}=310 \mathrm{~nm} \\
\mathrm{FI}=\frac{\mathrm{I}_{\mathrm{Em}} 450}{\mathrm{I}_{\mathrm{Em}} 500}, \text { at } \mathrm{E}_{\mathrm{x}}=370 \mathrm{~nm}
\end{gathered}
$$

\subsection{DBPs analysis}

Five categories of DBPs including four THMs, three HAAs, one HAN, one HNM and nine NAs were quantitatively analyzed. THMs measurement was conducted on a gas chromatograph-mass spectrometer (GC-MS) (Agilent 7890B-5977C, USA) equipped with a purge and trap autosampler and a DB-624 column (60 m×0.25 mm×1.4 $\mu \mathrm{m})$. For HAAs, samples were filtered with a $\mathrm{Ba} / \mathrm{Ag} / \mathrm{H}$ column and $0.2 \mu \mathrm{m}$ microporous membrane, and then analyzed on an ion chromatograph (IC) (Thermo Integrion HPIC, USA). HANs and HNMs analyses were performed on a GC equipped with an electron capture detector (GC-ECD) (Agilent 7890A) and a DB-17MS capillary column (30 m×0.25 mm×0.25 $\mu \mathrm{m})$. Solid phase extraction (SPE) and liquid chromatograph-mass spectrometer (LC-MS) (Shim-pack LCMS-8) were used for the measurement of NAs.

\subsection{Toxicity and ecological risk assessment of DBPs}

Both cytotoxicity and genotoxicity are widely used to assess the overall toxicity of DBPs in drinking water ${ }^{28}$. The unit cytotoxicity and genotoxicity index values were defined as the reciprocal of the median $\mathrm{LC}_{50}$ and median $\mathrm{CHO}$ SCGE genotoxic potency for each DBP, respectively ${ }^{46}$. Cytotoxicity and genotoxicity indices of each DBPs were calculated by multiplying unit toxicity indices and DBPs concentrations, as listed in Table S2 46,47. In addition, risk quotient (RQ) was used to assess the potential ecological risks of DBPs in aquatic ecosystems. Three different model organisms including fish, daphnid and green algae were evaluated at the acute level of DBPs using $\mathrm{LC}_{50}$ or $\mathrm{EC}_{50}$. RQs of each DBP 
409 for a certain taxonomic group were calculated by the following equation (4) 28,54 .

$$
\mathrm{RQ}=\frac{M E C}{L C_{50} \text { or } E C_{50}}
$$

410 Here, MEC is the concentration of DBPs in natural waters, and $\mathrm{LC}_{50}$ and $\mathrm{EC}_{50}$ of each

411 DBPs were derived from ECOSAR Program developed by USEPA (Table S3). RQ<0.1 is

412 regarded as no adverse effect; $0.1<R Q<1$ represents low risk; $1<R Q<10$ indicates

413 moderate risk; $R Q>10$ is considered adverse risk to aquatic organisms ${ }^{54,55}$.

\section{$414 \quad 5.7$ Statistical data analysis}

415 Differences in DBP concentrations between sites, lakes and rivers were examined using 416 one-way analysis of variance (ANOVA) at $p=0.05$ level. Non-parametric Spearman's 417 correlation analysis between DBPs, water physiochemical variables, and fluorescence 418 indices were performed by SPSS 24.0. Redundancy analysis (RDA) was used to explore 419 the relationships between DBPs, water physiochemical variables, and fluorescence 420 indices using Canoco 5.0.

\section{Contributions}

423 Y.L., J.Q. and D.Z. designed the whole work. X.Z., L.W. H.L., W.L., C.Y. and X.W. collected 424 water samples. S.C. did the chemical analysis. X.Z. coordinated data analyses and wrote 425 the first draft. Y.X., X.H. and D.Z. edited the manuscript.

\section{Acknowledgement}

428 The authors would like to thank the financial support from the Major Program of National 429 Natural Science Foundation of China (52091543) and Chinese Academy of Engineering 430 (2020-ZD-15). D.Z. also acknowledges the support of Chinese Government's Thousand 431 Talents Plan for Young Professionals. 


\section{Ethics declarations}

434 Competing interests

435 The authors declare no competing interests. 


\section{Reference}

4371 Chen, Y. F. et al. The presence of SARS-CoV-2 RNA in the feces of COVID-19 438 patients. Journal of Medical Virology 92, 833-840, (2020).

4392 Zhang, D. et al. SARS-CoV-2 spillover into hospital outdoor environments. $440 \quad$ medRxiv, 2020.2005.2012.20097105, (2020).

4413 Di Maria, F. et al. Minimization of spreading of SARS-CoV-2 via household waste 442 produced by subjects affected by COVID-19 or in quarantine. Sci Total Environ $443 \quad 743,140803,(2020)$.

4444 Wathore, R., Gupta, A., Bherwani, H. \& Labhasetwar, N. Understanding air and 445 water borne transmission and survival of coronavirus: Insights and way forward for 446 SARS-CoV-2. Sci Total Environ 749, 141486, (2020).

4475 Zhang, D. et al. Potential spreading risks and disinfection challenges of medical 448 wastewater by the presence of Severe Acute Respiratory Syndrome Coronavirus 4492 (SARS-CoV-2) viral RNA in septic tanks of Fangcang Hospital. Sci Total Environ $450 \quad 741,140445,(2020)$.

4516 Srivastav, A. L., Patel, N. \& Chaudhary, V. K. Disinfection by-products in drinking 452 water: Occurrence, toxicity and abatement. Environ Pollut 267, 115474, (2020).

4537 Zhang, H., Tang, W., Chen, Y. \& Yin, W. Disinfection threatens aquatic ecosystems. $454 \quad$ Science 368, 146-147, (2020).

4558 Sedlak, D. L. \& von Gunten, U. The Chlorine Dilemma. Science 331, 42-43, (2011).

4569 Yang, M., Zhang, X., Liang, Q. \& Yang, B. Application of (LC/)MS/MS precursor ion 457 scan for evaluating the occurrence, formation and control of polar halogenated 458 DBPs in disinfected waters: A review. Water Res 158, 322-337, (2019). 
45910 Du, Y. et al. Chlorinated effluent organic matter causes higher toxicity than

$460 \quad$ chlorinated natural organic matter by inducing more intracellular reactive oxygen $461 \quad$ species. Sci Total Environ 701, 134881, (2020).

46211 Alexandrou, L., Meehan, B. J. \& Jones, O. A. H. Regulated and emerging 463 disinfection by-products in recycled waters. Sci Total Environ 637-638, 1607-1616, 464 (2018).

46512 Kar, S. \& Senthilkumaran, B. in Disinfection By-products in Drinking Water (ed 466 Majeti Narasimha Vara Prasad) 393-411 (Butterworth-Heinemann, 2020).

46713 Yadav, S., Dhodpakar, R. \& Kapley, A. in Disinfection By-products in Drinking 468 Water (ed Majeti Narasimha Vara Prasad) 205-233 (Butterworth-Heinemann, 469 2020).

47014 Teixido, E., Pique, E., Gonzalez-Linares, J., Llobet, J. M. \& Gomez-Catalan, J. 471 Developmental effects and genotoxicity of 10 water disinfection by-products in 472 zebrafish. J. Water Health 13, 54-66, (2015).

47315 van Veldhoven, K. et al. Effects of exposure to water disinfection by-products in a 474 swimming pool: A metabolome-wide association study. Environ Int 111, 60-70, 475 (2018).

47616 Mohammadi, A. et al. Comparing THMs level in old and new water distribution 477 systems; seasonal variation and probabilistic risk assessment. Ecotox Environ $478 \quad$ Safe 192, 110286, (2020).

47917 Mian, H. R., Hu, G., Hewage, K., Rodriguez, M. J. \& Sadiq, R. Prioritization of 480 unregulated disinfection by-products in drinking water distribution systems for 481 human health risk mitigation: A critical review. Water Res 147, 112-131, (2018). 
48218 Grellier, J., Rushton, L., Briggs, D. J. \& Nieuwenhuijsen, M. J. Assessing the 483 human health impacts of exposure to disinfection by-products - A critical review 484 of concepts and methods. Environ Int 78, 61-81, (2015).

48519 Simpson, K. L. \& Hayes, K. P. Drinking water disinfection by-products: an $486 \quad$ Australian perspective. Water Res 32, 1522-1528, (1998).

48720 Thokchom, B. in Disinfection By-products in Drinking Water (ed Majeti $488 \quad$ Narasimha Vara Prasad) 59-81 (Butterworth-Heinemann, 2020).

48921 Ding, S. et al. The stability of chlorinated, brominated, and iodinated 490 haloacetamides in drinking water. Water Res 142, 490-500, (2018).

49122 Glezer, V., Harris, B., Tal, N., losefzon, B. \& Lev, O. Hydrolysis of haloacetonitriles:

492 LINEAR FREE ENERGY RELATIONSHIP, kinetics and products. Water Res 33, 493 1938-1948, (1999).

49423 Dubey, S., Gusain, D., Sharma, Y. C. \& Bux, F. in Disinfection By-products in 495 Drinking Water (ed Majeti Narasimha Vara Prasad) 371-391 (Butterworth$496 \quad$ Heinemann, 2020).

49724 Mazhar, M. A. et al. Chlorination disinfection by-products in municipal drinking 498 water - A review. Journal of Cleaner Production 273, 123159, (2020).

49925 Flury, M. \& Aramrak, S. Role of air-water interfaces in colloid transport in porous $500 \quad$ media: A review. Water Resources Research 53, 5247-5275, (2017).

50126 Wang, L. et al. Spatial variation of dissolved organic nitrogen in Wuhan surface 502 waters: Correlation with the occurrence of disinfection byproducts during the 503 COVID-19 pandemic. Water Res, 117138, (2021).

50427 Wardlaw, T., Salama, P., Brocklehurst, C., Chopra, M. \& Mason, E. Diarrhoea: why 
children are still dying and what can be done. The Lancet 375, 870-872, (2010).

$50628 \mathrm{Li}$, Z. et al. Occurrence and ecological risk assessment of disinfection byproducts

507 from chlorination of wastewater effluents in East China. Water Res 157, 247-257, $508 \quad$ (2019).

50929 Malliarou, E., Collins, C., Graham, N. \& Nieuwenhuijsen, M. J. Haloacetic acids in 510 drinking water in the United Kingdom. Water Res 39, 2722-2730, (2005).

51130 Kanan, A. \& Karanfil, T. Formation of disinfection by-products in indoor swimming 512 pool water: The contribution from filling water natural organic matter and swimmer 513 body fluids. Water Res 45, 926-932, (2011).

$51431 \quad$ Lee, J. et al. Production of various disinfection byproducts in indoor swimming pool 515 waters treated with different disinfection methods. International Journal of Hygiene 516 and Environmental Health 213, 465-474, (2010).

51732 Hynds, P. D., Thomas, M. K. \& Pintar, K. D. M. Contamination of Groundwater 518 Systems in the US and Canada by Enteric Pathogens, 1990-2013: A Review and $519 \quad$ Pooled-Analysis. Plos One 9, e93301, (2014).

52033 Wu, G., Yang, J., Jiang, H., Deng, Y. \& Lear, G. Distribution of potentially 521 pathogenic bacteria in the groundwater of the Jianghan Plain, central China. Int 522 Biodeterior Biodegradation 143, 104711, (2019).

52334 Foster, S. S. D. \& Chilton, P. J. Downstream of downtown: urban wastewater as 524 groundwater recharge. Hydrogeology Journal 12, 115-120, (2004).

52535 Fout, G. S., Borchardt, M. A., Kieke, B. A. \& Karim, M. R. Human virus and 526 microbial indicator occurrence in public-supply groundwater systems: meta527 analysis of 12 international studies. Hydrogeology Journal 25, 903-919, (2017). 
52836 Allen, A. S., Borchardt, M. A., Kieke, B. A., Dunfield, K. E. \& Parker, B. L. Virus

529 occurrence in private and public wells in a fractured dolostone aquifer in Canada.

$530 \quad$ Hydrogeology Journal 25, 1117-1136, (2017).

53137 Krasner, S. W., Mitch, W. A., McCurry, D. L., Hanigan, D. \& Westerhoff, P.

532 Formation, precursors, control, and occurrence of nitrosamines in drinking water:

533 A review. Water Res 47, 4433-4450, (2013).

53438 Alegbeleye, O. O. \& Sant'Ana, A. S. Manure-borne pathogens as an important

535 source of water contamination: An update on the dynamics of pathogen

536 survival/transport as well as practical risk mitigation strategies. International

537 journal of hygiene and environmental health 227, 113524, (2020).

53839 Bellou, M. I. et al. Interaction of human adenoviruses and coliphages with kaolinite 539 and bentonite. Sci Total Environ 517, 86-95, (2015).

54040 Pandey, P. K., Kass, P. H., Soupir, M. L., Biswas, S. \& Singh, V. P. Contamination

541 of water resources by pathogenic bacteria. AMB Express 4, (2014).

$54241 \mathrm{Xu}, \mathrm{X}$. et al. EEM-PARAFAC characterization of dissolved organic matter and its 543 relationship with disinfection by-products formation potential in drinking water 544 sources of northeastern China. Sci Total Environ 774, 145297, (2021).

54542 Jutaporn, P., Armstrong, M. D. \& Coronell, O. Assessment of C-DBP and N-DBP 546 formation potential and its reduction by MIEX® DOC and MIEX® GOLD resins 547 using fluorescence spectroscopy and parallel factor analysis. Water Res 172, $548 \quad 115460,(2020)$.

54943 Jiang, L. et al. The influence of e-waste recycling on the molecular ecological 550 network of soil microbial communities in Pakistan and China. Environ Pollut 231, 
173-181, (2017).

$55244 \mathrm{Fu}, \mathrm{K}$. et al. Sucralose and acesulfame as an indicator of domestic wastewater 553 contamination in Wuhan surface water. Ecotox Environ Safe 189, 109980, (2020).

55445 Feng, H., Ruan, Y., Wu, R., Zhang, H. \& Lam, P. K. S. Occurrence of disinfection 555 by-products in sewage treatment plants and the marine environment in Hong Kong. $556 \quad$ Ecotox Environ Safe 181, 404-411, (2019).

55746 Ding, H. et al. Occurrence, profiling and prioritization of halogenated disinfection 558 by-products in drinking water of China. Environmental Science: Processes \& $559 \quad$ Impacts 15, 1424-1429, (2013).

56047 Wagner, E. D. \& Plewa, M. J. CHO cell cytotoxicity and genotoxicity analyses of 561 disinfection by-products: An updated review. J Environ Sci-China 58, 64-76, (2017).

56248 Hellmér, M. et al. Detection of Pathogenic Viruses in Sewage Provided Early 563 Warnings of Hepatitis A Virus and Norovirus Outbreaks. Appl. Environ. Microbiol. $564 \quad 80,6771,(2014)$.

56549 Pennington, H. Escherichia coli O157. The Lancet 376, 1428-1435, (2010).

56650 Shin, H. et al. Foodborne Viruses Detected Sporadically in the Fresh Produce and 567 Its Production Environment in South Korea. Foodborne Pathogens and Disease $568 \quad 16,411-420,(2019)$.

56951 Plewa, M. J. \& Wagner, E. D. in Encyclopedia of Environmental Health (Second 570 Edition) (ed Jerome Nriagu) 559-566 (Elsevier, 2019).

57152 Xin, C., Cheng, Z., You, Z., Bai, H. \& Wang, J. Using EEM fluorescence to 572 characterize the membrane integrity of membrane bioreactor (MBR). Journal of 573 Membrane Science 610, 118356, (2020). 
57453 Oliveira, H., Santos, C., Paterson, R., Gusmão, N. \& Lima, N. Fungi from a

575 Groundwater-Fed Drinking Water Supply System in Brazil. International Journal of

$576 \quad$ Environmental Research and Public Health 13, 304, (2016).

57754 Hela, D. G., Lambropoulou, D. A., Konstantinou, I. K. \& Albanis, T. A. 578 Environmental monitoring and ecological risk assessment for pesticide 579 contamination and effects in Lake Pamvotis, northwestern Greece. Environ Toxicol $580 \quad$ Chem 24, 1548-1556, (2005).

58155 Aydin, S., Aydin, M. E., Ulvi, A. \& Kilic, H. Antibiotics in hospital effluents:

582 occurrence, contribution to urban wastewater, removal in a wastewater treatment 583 plant, and environmental risk assessment. Environ Sci Pollut $R$ 26, 544-558, $584 \quad$ (2019).

58556 Kurajica, L. et al. Disinfection by-products in Croatian drinking water supplies with 586 special emphasis on the water supply network in the city of Zagreb. J Environ $587 \quad$ Manage 276, 111360, (2020).

58857 Srivastav, A. L. \& Kaur, T. in Disinfection By-products in Drinking Water (ed 589 Majeti Narasimha Vara Prasad) 433-450 (Butterworth-Heinemann, 2020).

59058 La Rosa, G. et al. First detection of SARS-CoV-2 in untreated wastewaters in Italy. 591 Sci Total Environ 736, 139652, (2020). 
Table 1. Water physiochemical variables in lakes and rivers of Wuhan.

\begin{tabular}{cccccccccc}
\hline & $\boldsymbol{n}$ & $\mathbf{p H}$ & $\begin{array}{c}\text { Conductivity } \\
(\boldsymbol{\mu S} / \mathbf{c m})\end{array}$ & $\begin{array}{c}\text { Turbidity } \\
(\mathbf{N T U})\end{array}$ & $\begin{array}{c}\mathbf{N H}_{3}-\mathbf{N} \\
(\mathbf{m g} / \mathbf{L})\end{array}$ & $\begin{array}{c}\text { TN } \\
(\mathbf{m g} / \mathbf{L})\end{array}$ & $\begin{array}{c}\text { TP } \\
(\mathbf{m g} / \mathbf{L})\end{array}$ & $\begin{array}{c}\text { COD } \\
(\mathbf{m g} / \mathbf{L})\end{array}$ \\
\hline HJH & 12 & $6.64 \pm 0.15$ & $236.5 \pm 62.4$ & $6.95 \pm 1.77$ & $0.21 \pm 0.05$ & $0.81 \pm 0.16$ & $0.09 \pm 0.02$ & $12.8 \pm 2.57$ & $16.0 \pm 9.03$ \\
NH & 10 & $7.41 \pm 0.27$ & $281.2 \pm 28.9$ & $9.62 \pm 3.46$ & $0.52 \pm 0.15$ & $1.73 \pm 0.51$ & $0.17 \pm 0.08$ & $28.7 \pm 4.36$ & $9.89 \pm 6.02$ \\
LZH & 9 & $8.00 \pm 0.04$ & $114.0 \pm 4.55$ & $1.85 \pm 0.84$ & $0.10 \pm 0.03$ & $1.00 \pm 0.21$ & $0.02 \pm 0.01$ & $6.19 \pm 1.75$ & $5.10 \pm 1.75$ \\
MSH & 8 & $8.22 \pm 0.26$ & $251.7 \pm 40.8$ & $13.00 \pm 6.12$ & $0.45 \pm 0.10$ & $2.94 \pm 0.99$ & $0.19 \pm 0.05$ & $37.9 \pm 5.80$ & $7.46 \pm 1.44$ \\
HGH & 11 & $8.63 \pm 0.10$ & $240.1 \pm 19.7$ & $5.85 \pm 2.77$ & $0.20 \pm 0.05$ & $0.77 \pm 0.14$ & $0.04 \pm 0.01$ & $14.6 \pm 2.46$ & $5.02 \pm 0.95$ \\
DH & 12 & $8.45 \pm 0.22$ & $287.7 \pm 23.0$ & $3.55 \pm 1.41$ & $0.12 \pm 0.02$ & $0.52 \pm 0.05$ & $0.03 \pm 0.01$ & $14.2 \pm 1.91$ & $5.34 \pm 1.49$ \\
HH & 8 & $6.88 \pm 0.54$ & $206.4 \pm 41.2$ & $38.81 \pm 32.80$ & $0.41 \pm 0.15$ & $2.01 \pm 1.07$ & $0.20 \pm 0.14$ & $61.5 \pm 21.7$ & $8.00 \pm 0.75$ \\
JYH & 12 & $7.77 \pm 0.09$ & $321.2 \pm 53.4$ & $6.37 \pm 3.77$ & $0.20 \pm 0.10$ & $1.13 \pm 0.23$ & $0.08 \pm 0.07$ & $18.10 \pm 2.91$ & $4.95 \pm 1.91$ \\
TXH & 11 & $8.11 \pm 0.17$ & $358.6 \pm 59.9$ & $11.39 \pm 4.05$ & $0.36 \pm 0.05$ & $1.58 \pm 0.36$ & $0.21 \pm 0.06$ & $35.0 \pm 5.93$ & $6.96 \pm 1.54$ \\
YR & 11 & $7.86 \pm 0.23$ & $262.5 \pm 12.8$ & $2.06 \pm 0.46$ & $0.08 \pm 0.02$ & $1.52 \pm 0.26$ & $0.03 \pm 0.01$ & $2.97 \pm 1.80$ & $2.72 \pm 0.18$ \\
HR & 6 & $7.57 \pm 0.04$ & $285.3 \pm 18.4$ & $2.44 \pm 0.59$ & $0.08 \pm 0.01$ & $1.07 \pm 0.13$ & $0.03 \pm 0.01$ & $8.33 \pm 0.96$ & $2.99 \pm 0.16$ \\
\hline
\end{tabular}


Table2. Comparison of DBPs compositions between this study and other waters.

\begin{tabular}{|c|c|c|c|c|c|c|}
\hline Water sample & THMs ( $\mu \mathrm{g} / \mathrm{L})$ & HAAs ( $\mu \mathrm{g} / \mathrm{L})$ & HANs ( $\mu \mathrm{g} / \mathrm{L})$ & HNMs ( $\mu \mathrm{g} / \mathrm{L})$ & NAs ( $\mu \mathrm{g} / \mathrm{L})$ & Reference \\
\hline \multirow{4}{*}{ Drinking water } & $0.7-32.8$ & $0-17.2$ & N.D. & N.D. & N.D. & 56 \\
\hline & $27.6-50.9$ & $35.1-94.6$ & N.D. & N.D. & N.D. & 29 \\
\hline & $0.13-458$ & $0.16-136$ & $0.12-30$ & N.D. & N.D. & 57 \\
\hline & $31.9-115.7$ & $0-27.3$ & $4.0-20.7$ & N.D. & N.D. & 58 \\
\hline Wastewater & $2.3-60.7$ & $7.3-120.1$ & $2.9-48.6$ & $1.0-7.4$ & $0.35-1.19$ & 28 \\
\hline \multirow[t]{2}{*}{ effluents } & $2.47-4.45$ & N.D. & $0.14-0.66$ & N.D. & N.D. & 45 \\
\hline & N.D. -49.0 & $35.2-747.1$ & $0.8-14.3$ & N.D. & N.D. & 31 \\
\hline \multirow[t]{2}{*}{ Swimming pools } & $75-104.0$ & N.D.-119 & N.D. & $0.7-1.7$ & N.D. & 30 \\
\hline & $41.3-57.4$ & $90.1-105.6$ & $15.1-20.6$ & N.D. & N.D. & 58 \\
\hline This study & $0.99-14.3$ & $33.8-856.1$ & $0-1.09$ & $0-4.62$ & $0.0414-0.0861$ & \\
\hline
\end{tabular}




\section{Figure captions}

600 Figure 1. Geographic location of 110 sampling sites in nine lakes and two rivers of Wuhan, 601 China.

602 Figure 2. Total amount (A) and composition (B) of key DBPs in lakes and rivers of Wuhan 603 in the initial stage of COVID-19.

604 Figure 3. The composition of individual THMs (A), HANs (B), HNMs (C), and NAs (D) in 605 lakes and rivers of Wuhan in the initial stage of COVID-19.

606 Figure 4. Cytotoxicity indices (A) and fraction (B) of DPBs in in nine lakes and two rivers 607 of Wuhan. Genotoxicity indices (C) and fraction (D) of DPBs in in nine lakes and two rivers 608 of Wuhan.

609 Figure 5. Ecological risk assessment by RQ values of DBPs in rivers and lakes of Wuhan.

610 (A) Fish; (B) daphnid; (C) green algae.

611 Figure 6. (A) Typical excitation-emission matrix (EEM) of dissolved organic matters

612 (DOMs) in lakes and rivers of Wuhan. (B) Composition of fluorescence regional 613 integration (FRI) in different lakes and rivers. (C) Fluorescence indices (FI) of DOMs in 614 different lakes and rivers.

615 Figure 7. (A) Correlation analysis between BBPs, water physiochemical variables, 616 fluorescence regional integration $(\mathrm{FRI})$ and fluorescence indices $(\mathrm{FI})$ in lakes and rivers 617 of Wuhan. Blue and red ellipses represent significantly positive and negative correlations, 618 respectively. (B) Redundancy analysis (RDA) score plot of DBPs and water 619 physiochemical variables. Key variables (explanation) include conductivity (10.4\%, $620 p=0.002)$, TOC $(7.1 \%, p=0.004)$, turbidity $(3.3 \%, p=0.02)$ and $\mathrm{NH}_{3}-\mathrm{N}(3.0 \%, p=0.042) .(\mathrm{C})$ 621 RDA score plot of DBPs and fluorescence indices from excitation-emission matrix (EEM). 622 Key fluorescence indices (explanation) include Peak T/C (4.1\%, $p=0.02)$ and Region IV $623(3.9 \%, p=0.01)$. 

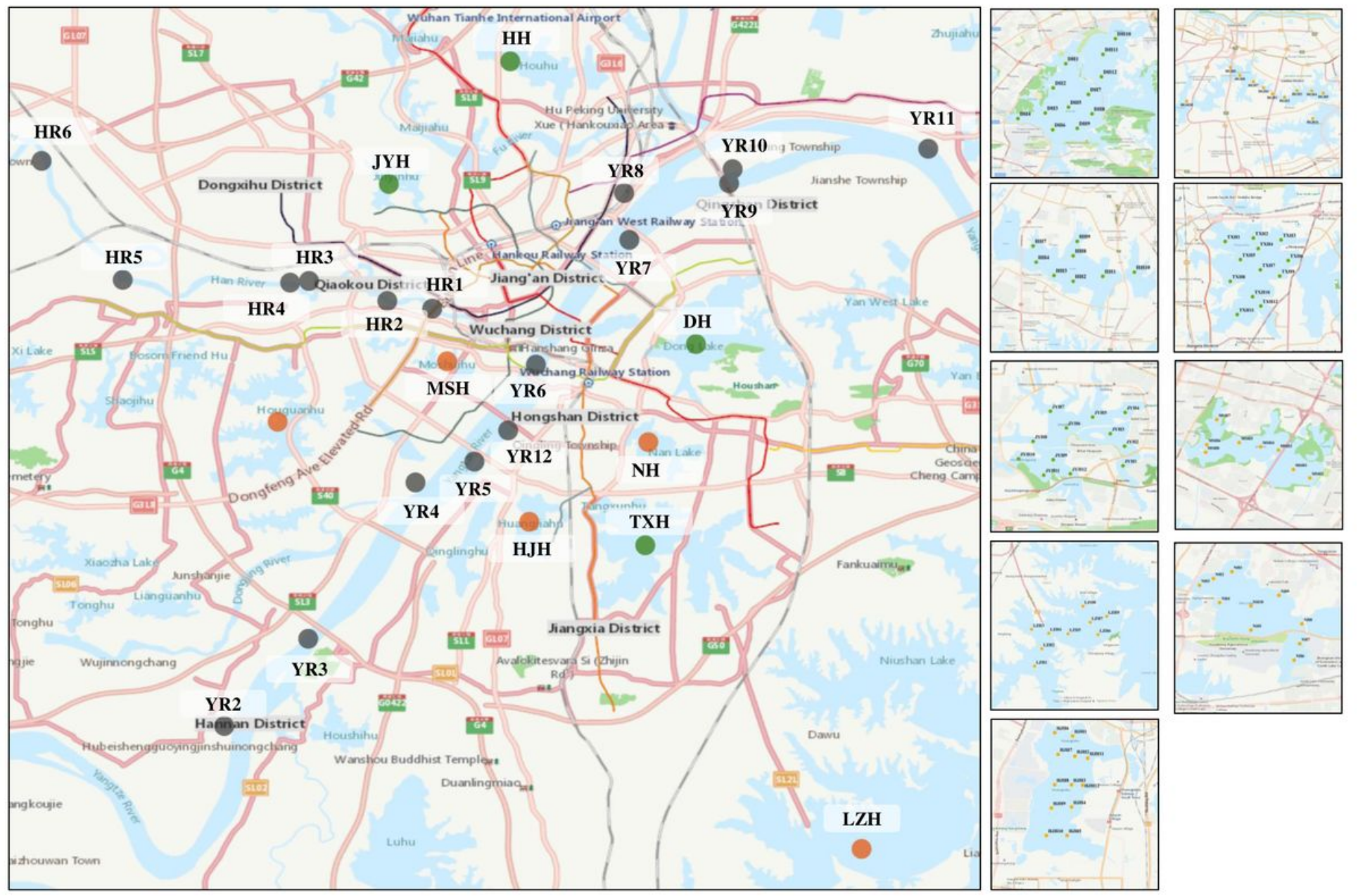

\section{Figure 1}

Geographic location of 110 sampling sites in nine lakes and two rivers of Wuhan, China. Note: The designations employed and the presentation of the material on this map do not imply the expression of any opinion whatsoever on the part of Research Square concerning the legal status of any country, territory, city or area or of its authorities, or concerning the delimitation of its frontiers or boundaries. This map has been provided by the authors. 

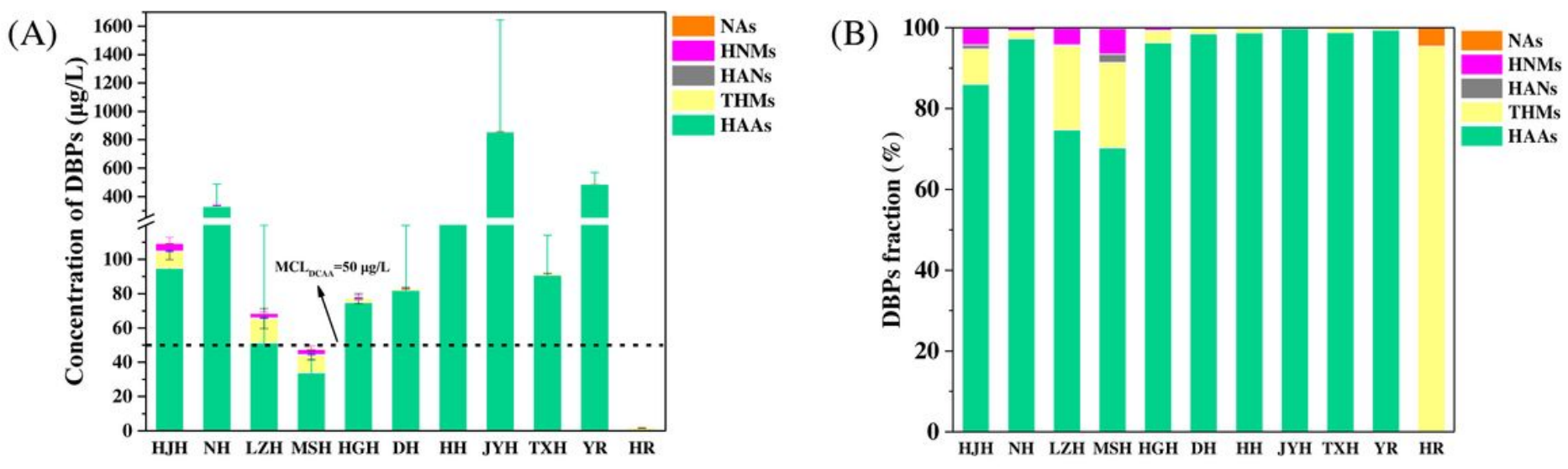

Figure 2

Total amount (A) and composition (B) of key DBPs in lakes and rivers of Wuhan in the initial stage of COVID-19. 
(A)

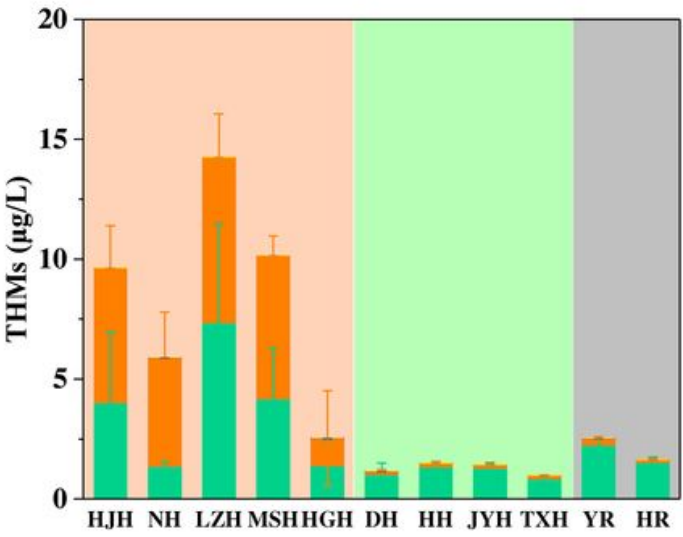

(C)

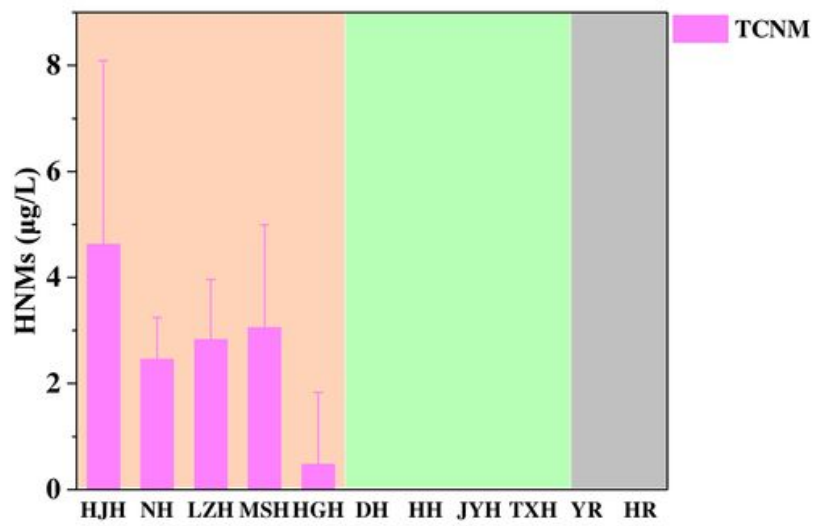

(B)

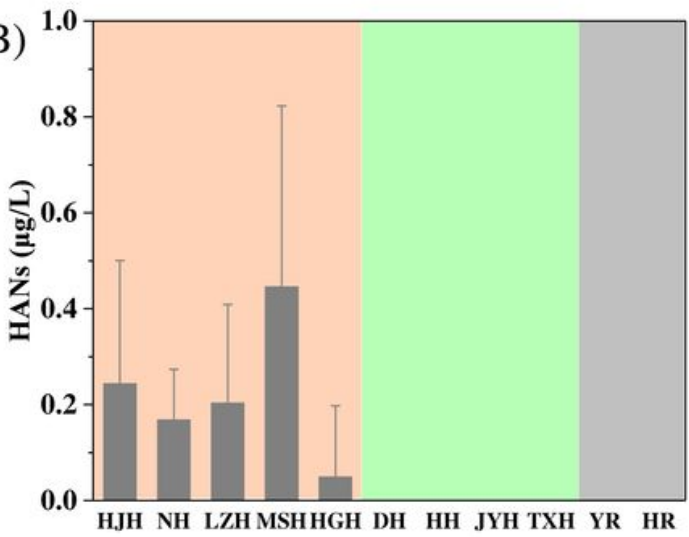

TCAN

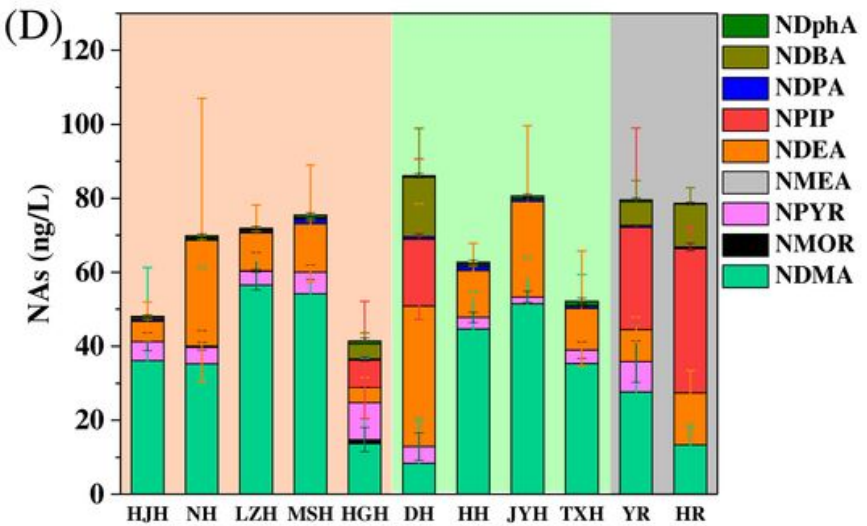

\section{Figure 3}

The composition of individual THMs (A), HANs (B), HNMs (C), and NAs (D) in lakes and rivers of Wuhan in the initial stage of COVID-19. 
(A)

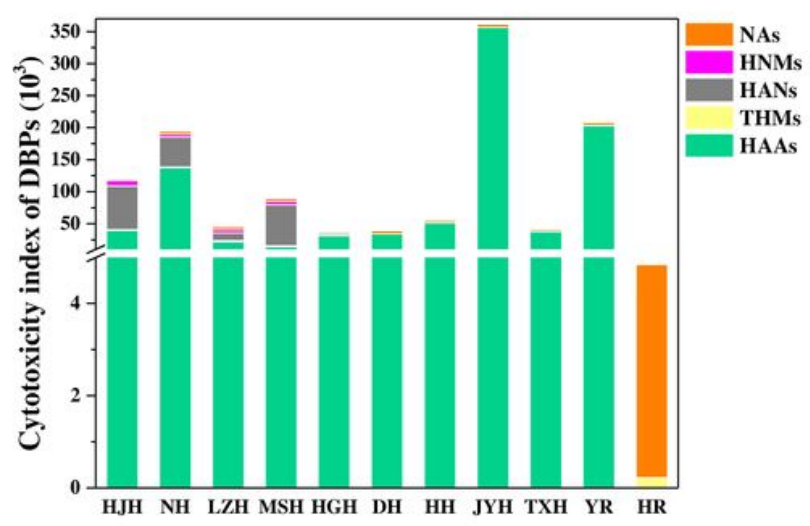

(C)

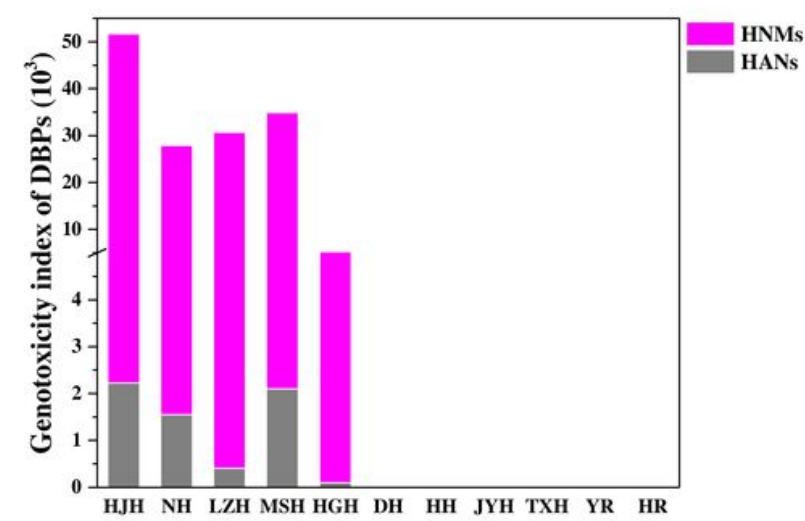

(B)

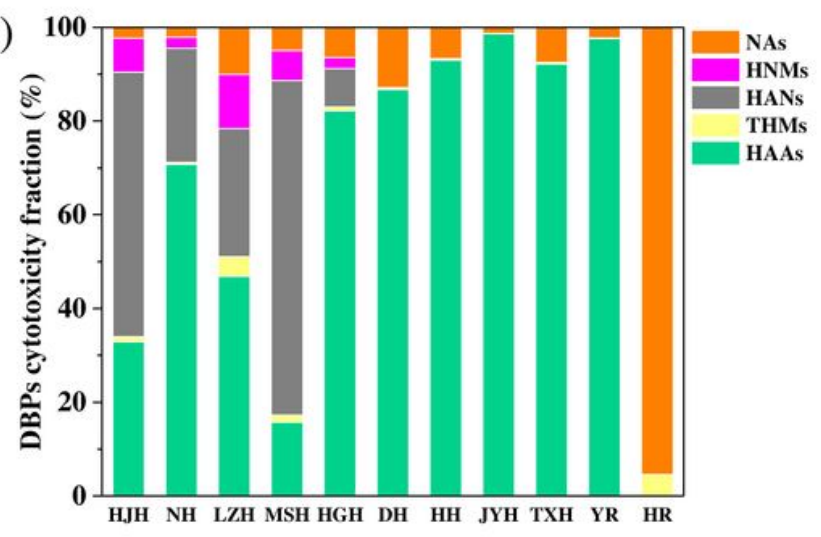

(D)

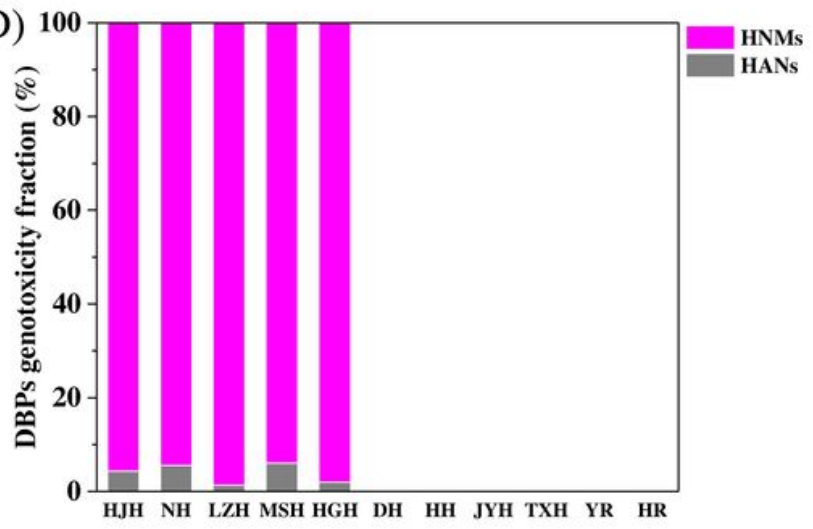

Figure 4

Cytotoxicity indices (A) and fraction (B) of DPBs in in nine lakes and two rivers of Wuhan. Genotoxicity indices (C) and fraction (D) of DPBs in in nine lakes and two rivers of Wuhan. 

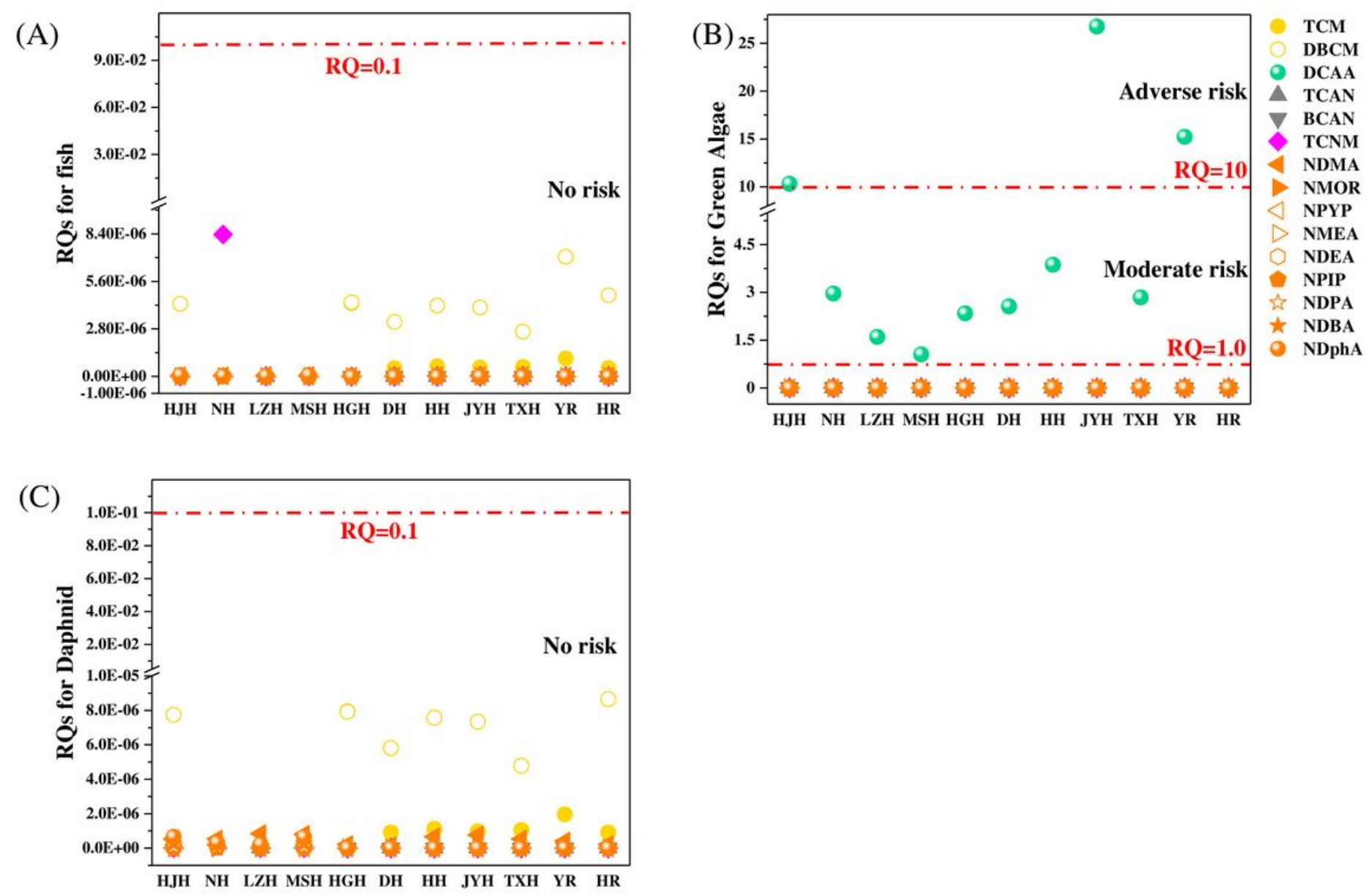

Figure 5

Ecological risk assessment by RQ values of DBPs in rivers and lakes of Wuhan. (A) Fish; (B) daphnid; (C) green algae. 
(A)
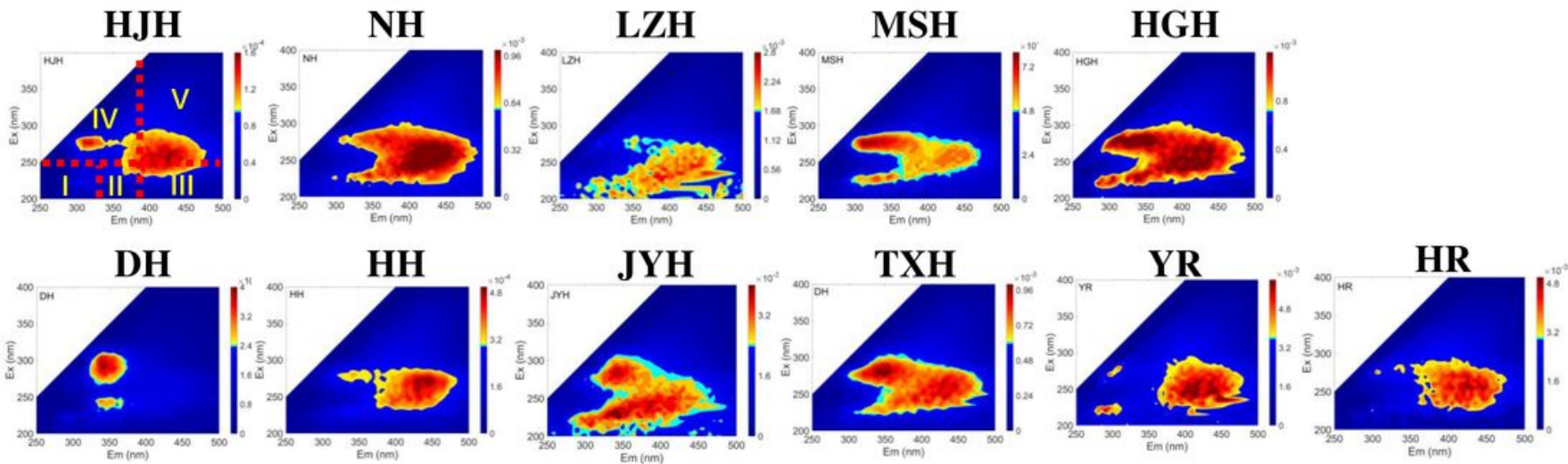

(B)
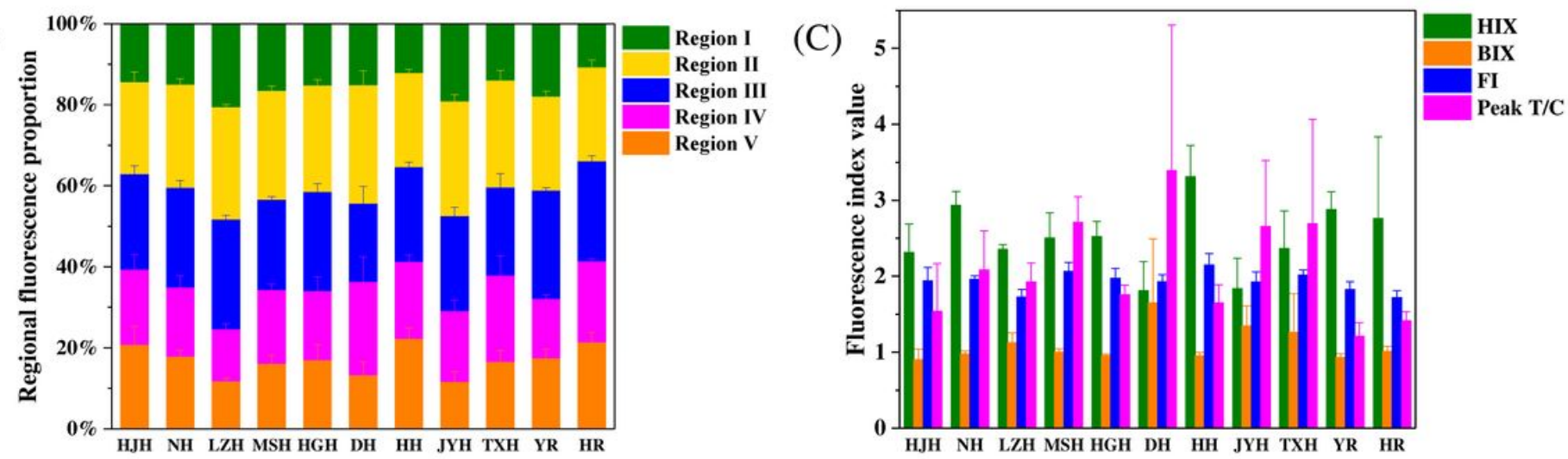

Figure 6

(A) Typical excitation-emission matrix (EEM) of dissolved organic matters (DOMs) in lakes and rivers of Wuhan. (B) Composition of fluorescence regional integration (FRI) in different lakes and rivers. (C) Fluorescence indices $(\mathrm{FI})$ of DOMs in different lakes and rivers. 
(A)

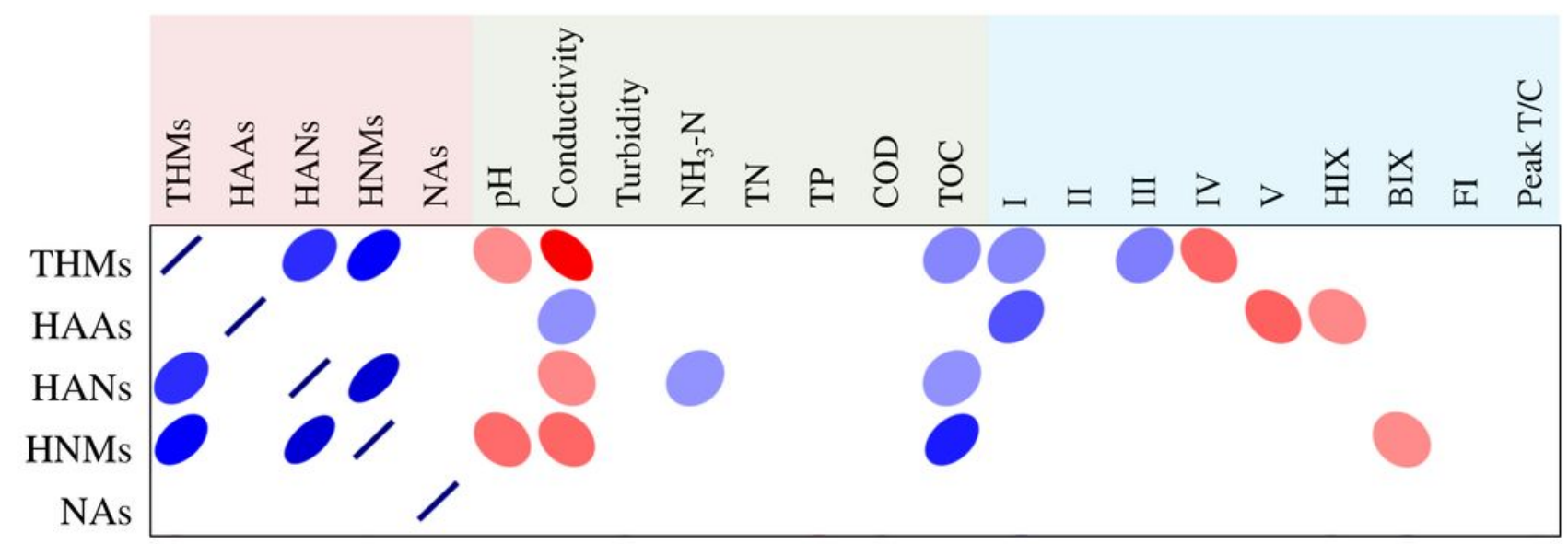

(B)

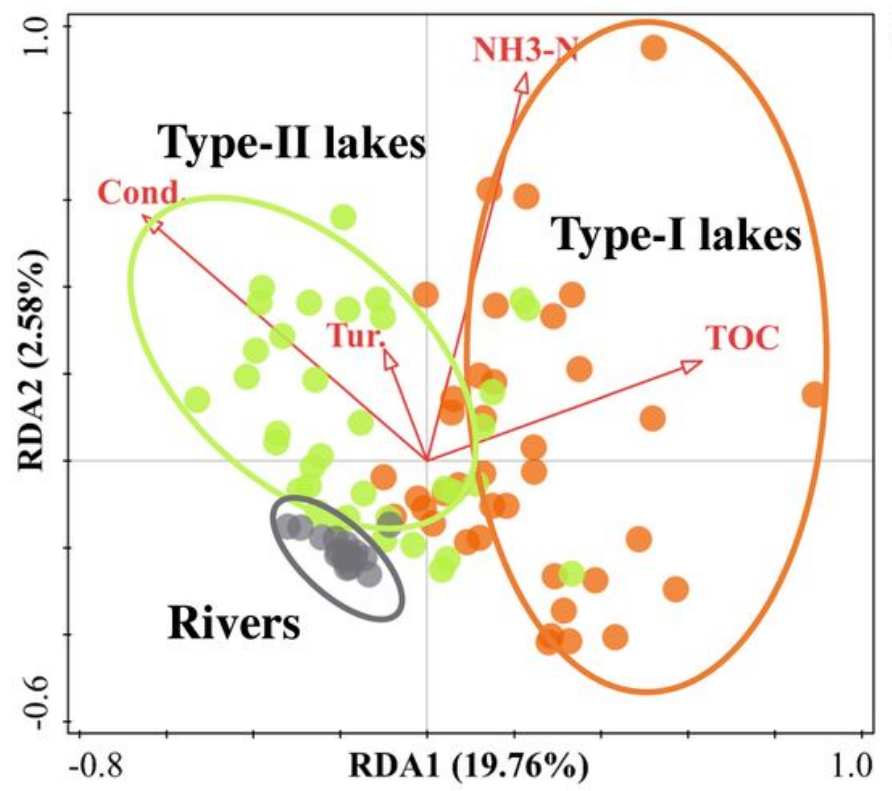

(C)

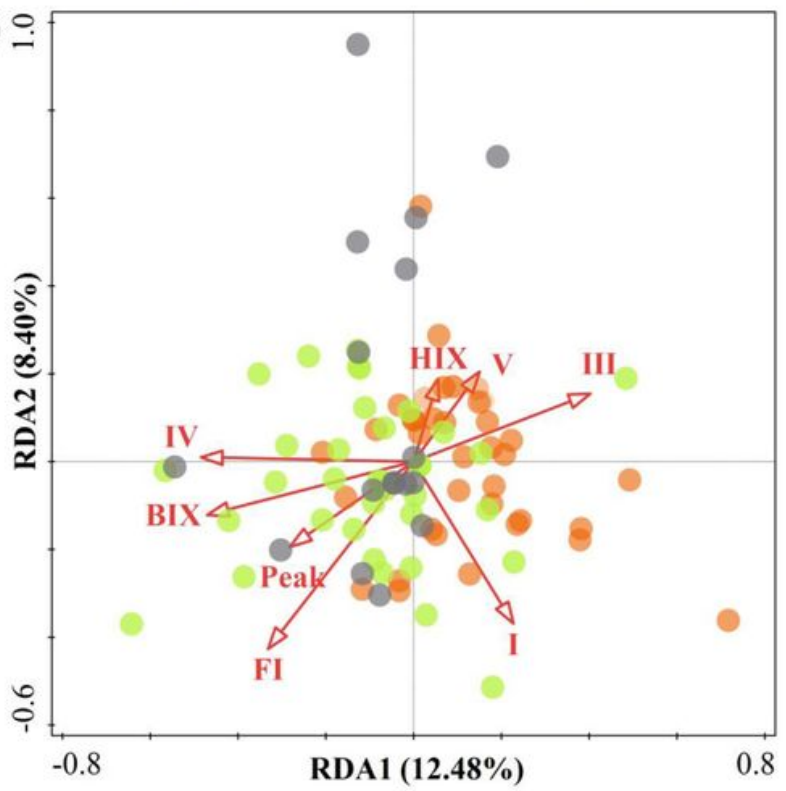

Figure 7

(A) Correlation analysis between BBPs, water physiochemical variables, fluorescence regional integration (FRI) and fluorescence indices (FI) in lakes and rivers of Wuhan. Blue and red ellipses represent significantly positive and negative correlations, respectively. (B) Redundancy analysis (RDA) score plot of DBPs and water physiochemical variables. Key variables (explanation) include conductivity $(10.4 \%$, $\mathrm{p}=0.002), \operatorname{TOC}(7.1 \%, \mathrm{p}=0.004)$, turbidity $(3.3 \%, \mathrm{p}=0.02)$ and NH3-N $(3.0 \%, \mathrm{p}=0.042)$. (C) RDA score plot of DBPs and fluorescence indices from excitation-emission matrix (EEM). Key fluorescence indices (explanation) include Peak T/C (4.1\%, $\mathrm{p}=0.02)$ and Region IV $(3.9 \%, \mathrm{p}=0.01)$.

\section{Supplementary Files}

This is a list of supplementary files associated with this preprint. Click to download.

- SupportingInformation.docx 